\title{
Sabe aquele gol que o Pelé não fez? Eu fiz!: a trajetória esportiva de Duda (2018), de Silvana Goellner e Suellen Ramos
}

\author{
Thiago Carlos Costa \\ Universidade Federal de Minas Gerais, Belo Horizonte/Brasil \\ Doutorando em Estudos do Lazer, UFMG \\ thiagoc_costa@yahoo.com.br
}

O livro Sabe aquele gol que o Pelé não fez? Eu fiz!: a trajetória esportiva de Duda, de autoria das pesquisadoras Silvana Vilodre Goellner e Suellen dos Santos Ramos, publicado pela editora carioca, Multifoco, no selo Drible de Letra, apresenta a trajetória esportiva de Eduarda Maranguello Luizelli, a Duda. Logo na capa da obra, a jogadora se destaca trajada com o uniforme do Sport Club Internacional de Porto Alegre, agremiação gaúcha que marcou a sua vida esportiva.

Esse livro, fruto da dissertação de mestrado de Suellen Ramos sob a orientação de Silvana Goellner, apresenta a biografia de Duda, a trajetória esportiva e pessoal da atleta, bem como uma contextualização completa sobre o panorama do futebol de mulheres praticado no Brasil, como bem salienta as autoras logo no início da obra:

[...] entendemos ser política a divulgação da presença das mulheres no futebol brasileiro, visto que desde os seus primórdios elas estiveram presentes, seja como jogadoras, seja como torcedoras. Presença essa que foi gradativamente se ampliando, mas que a história oficial da modalidade não se preocupou em registrar. Escrever sobre a Duda é também escrever sobre a história do futebol de mulheres no Brasil. Reconhecer seu protagonismo significa, em última instância, afirmar que o futebol também lhes pertence. ${ }^{1}$

A delimitação do lugar das mulheres no futebol permeia de forma bem direta por toda a obra e nos ajuda muito a justificar a força deste livro, que é dividido por capítulos intitulados: "Pré-jogo", "Preleção", "Primeiro tempo" e “Segundo tempo". Logo no prefácio, descobrimos a construção de sentido em torno

${ }^{1}$ GOELLNER; RAMOS. Sabe aquele gol que o Pelé não fez? Eu fiz!: a trajetória esportiva de Duda, p. 17. 
do título da obra sobre Duda - Sabe aquele gol que o Pelé não fez?. Com apenas 13 anos, jogando pelo Internacional no Campeonato Brasileiro da modalidade, a jogadora fez o gol decisivo da partida. Esse feito marca a trajetória esportiva de Duda, que serve de título para sua biografia, mostrando a superação sobre o futebol masculino ao referenciar a famosa tentativa de gol do Pelé contra a seleção da Tchecoslováquia na Copa de 1970, quando o brasileiro viu o goleiro adversário adiantado e, pouco depois da intermediária do seu campo de defesa, a uma distância de quase 70 metros da baliza adversária, viu a bola caprichosamente passar rente a trave e não entrar. O lance ficou marcado como um dos mais famosos de Pelé.

Sobre a biografia, podemos destacar aqui a sua função como importante gênero literário que ganhou muita força no mercado editorial na segunda metade do século XIX, na Europa, trazendo construções narrativas de grandes personalidades históricas, sendo homens e mulheres. Essas biografias passavam por uma metodologia factual e positivista e celebravam essas trajetórias pessoais a fim de justificar o protagonismo das personagens em eventos históricos em que tiveram ligações diretas e decisivas. Reforçava-se ali a história das grandes personalidades europeias que, logo mais tarde, no século $\mathrm{XX}$, seriam somadas às vidas de celebridades do mundo cultural, próximo do formato que encontramos nas publicações atuais no mercado editorial.

Em relação à biografia enquanto fonte de pesquisa e produção acadêmica na história, esse tipo de produção ganha força na segunda metade do século XX, com a chamada nova história cultural e, mais adiante, a chamada micro-história. Foi nessa segunda metodologia de pesquisa que Suellen e Silvana pautaram suas pesquisas e esta publicação, além do uso constante e produtivo de outra metodologia acadêmica, a história oral.

Ao longo do livro, observamos um detalhado trabalho de micro-história, no qual as autoras situam Duda no contexto de reativação do futebol de mulheres no Brasil, lembrando aqui o período de proibição dessa prática esportiva para as mulheres brasileiras entre o início da década de 1940 e o final dos anos 1970. Valendo disso, as pesquisadoras trazem a trajetória de Duda para dentro de um contexto macro da história do futebol praticado por mulheres no Brasil, 
exemplificando e detalhando as dificuldades vivenciadas por elas nessa prática esportiva. Fazendo uso da história oral, Suellen e Silvana apresentam relatos de Duda, bem como de seus pais, companheiro, colegas de profissão e, mais adiante, de suas alunas. 0 uso desses depoimentos contribui para dar voz às testemunhas oculares da história e ajudam a construir a narrativa em torno da trajetória esportiva de Eduarda Luizelli, considerando o fato de que o livro é dividido em duas grandes partes: a primeira aborda a Duda, jogadora de futebol, e a segunda traz a personalidade gestora de futebol da atleta.

No capítulo "Primeiro tempo" são apresentados a infância e os primeiros passos de Eduarda rumo ao futebol, além do estímulo dos pais e a frequência nos jogos do Internacional como torcedora, reforçando ainda mais sua identidade com o clube colorado de Porto Alegre. Na sequência, a inserção precoce de Duda no time adulto do Inter, com apenas 13 anos de idade, é explorada pelas autoras para mostrar a falta de estrutura do futebol praticado pelas mulheres e como as oportunidades eram aproveitadas naquele momento. Um mérito louvável do livro, e que ajuda a tornar a leitura mais fluida e interessante para o leitor, são as cuidadosas notas de rodapé ao citar cada jogadora. Essas notas, ora mescladas com depoimentos das colegas sobre Duda, ora sobre um evento relacionado ao futebol, ajudam a formatar a relação da pesquisa com a história oral e a micro-história, trazendo para ao público um panorama detalhado do futebol brasileiro feminino nos anos 1980, 1990 e início de 2000.

Ao longo do capítulo, podemos observar a consolidação de Duda enquanto atleta de futebol dentro de um contexto completamente precário e desvalorizado no Rio Grande do Sul e no Brasil. Os relatos descrevem problemas de falta de salários, a busca por clubes que valorizassem o futebol de mulheres, as viagens de ônibus para as raras competições regionais e nacionais, além da continuidade dessas próprias competições. Paralelamente a este cenário de busca por visibilidade e afirmação do futebol praticado por mulheres, Suellen e Silvana problematizam os meios utilizados pela mídia para divulgar o trabalho do futebol feminino. A forma como as jogadoras são apresentadas pela mídia é, em sua maioria, por meio da exploração da feminilidade e da exaltação da beleza das atletas, abordando a vaidade, os corpos, os cabelos, as unhas e outros elementos de "venda" 
de uma imagem dissociada da robustez e virilidade do futebol praticado por homens. Assim, neste cenário, atletas do Internacional, como Duda e Bel, são alçadas ao status de musas do futebol praticado por mulheres no Rio Grande do Sul.

Outro ponto de destaque do livro é a busca de Duda por afirmação esportiva em uma modalidade com pouquíssima valorização por parte de dirigentes, patrocinadores e mídia. Inclusive, a própria construção de uma seleção brasileira de futebol jogada por mulheres se conecta à trajetória de Duda, tornando-se simultaneamente sua alegria e frustração, pois, por meio das participações na seleção brasileira, Duda consolida-se como grande nome do futebol feminino gaúcho, ganha projeção nacional e internacional, jogando futebol na Itália justamente pela visibilidade que teve atuando na seleção brasileira. Por outro lado, mesmo atuando bem em amistosos e em competições sul-americanas, Duda não foi convocada para jogar as Copas do Mundo e nem os Jogos Olímpicos. Boa parte dessa ausência se justifica pela pouca visibilidade do futebol gaúcho e, ao mesmo tempo, em razão da consolidação do futebol de mulheres jogado no Rio de Janeiro e em São Paulo, com clubes como Radar e Saad.

No capítulo "Segundo tempo", o livro apresenta uma Duda que, dentro do contexto incerto do futebol de mulheres, estudou Educação Física visando um projeto de formação de mulheres atletas de futebol. Essa Duda, como gestora de futebol, mostra seu amadurecimento pessoal e profissional, e o foco na formação e profissionalização do futebol feminino no Rio Grande do Sul. Assim, a batalha de Eduarda passa das quatro linhas para os bastidores e o cenário do futebol de mulheres, mesmo tendo passado mais de três décadas desde sua retomada oficial no Brasil, ainda engatinha em termos de organização e visibilidade. Vale lembrar que Duda, atualmente, é coordenadora do futebol feminino do Sport Club Internacional.

Portanto, este é um livro importante e extremamente necessário para quem deseja estudar o tema ou admira histórias de resistência. A obra traz exatamente esse poder de luta, ao abordar a trajetória de Duda para conseguir praticar futebol, conectada às histórias de outras mulheres contemporâneas a ela que batalham dentro e fora dos gramados por visibilidade e reconhecimento. Neste ano de 2019, contudo, a obrigatoriedade, por parte da Conmebol, dos clubes de investir no desenvolvimento do futebol feminino como pré-requisito para participarem das 
principais competições masculinas da América do Sul, as Copas Libertadores e SulAmericana, pode ajudar compulsoriamente no processo de profissionalização da jogadoras. Também vale ressaltar que, neste ano, acontecerá na França, entre os meses de junho e julho, a oitava edição da Copa do Mundo de Futebol Feminino. Somando-se a esse evento macro, a Confederação Brasileira de Futebol, promoverá o Campeonato Brasileiro de Futebol Feminino, séries A e B, com a participação de equipes tradicionais do futebol masculino e de equipes já fortemente presentes do futebol feminino.

Por fim, fica aqui o desejo por mais biografias como esta de Duda e de suas companheiras que lutaram e ainda lutam a favor do futebol feminino e da valorização do trabalho de pesquisa e memória do futebol praticado por mulheres no Brasil, como o que vem sendo coordenado pela professora Silvana Goellner em seu grupo de estudos.

\section{REFERENCIAS}

GOELLNER, Silvana Vilodre; RAMOS, Suellen dos Santos. Sabe aquele gol que o Pelé não fez? Eu fiz!: a trajetória esportiva de Duda. Rio de Janeiro: Editora Multifoco, 2018. 132 páginas. 